\title{
COMO INCENTIVAR A TUTELA AMBIENTAL ATRAVÉS DE BENEFÍCIOS TRIBUTARIOS EM TERRITÓRIO BRASILEIRO
}

Jane Elisabeth Cesca ${ }^{33}$

\begin{abstract}
Resumo: Apesar da exigência constitucional de respeito ao meio ambiente, a atividade empresarial tem desconsiderado os efeitos maléficos de muitas de suas ações. Raros, são os empresários estabelecidos no Brasil que têm preocupação com a questão da exploração indiscriminada dos recursos naturais não-renováveis e com o desequilíbrio que causam ao ecossistema. $\mathrm{O}$ estudo mostra aspectos da tutela ambiental através da utilização dos tributos já existentes no ordenamento jurídico nacional, como forma de incentivo aos contribuintes, sejam empresários ou não, desonerando-os do pagamento. Apresenta ainda as possibilidades já exploradas por alguns Estados e Municípios.

Palavras-chave: tutela ambiental, instrumentos não-jurisdicionais, tributos.
\end{abstract}

Abstract: Despite the constitutional requirement of respect for the environment, the entrepreneurial activity has disregard, the evil effects of many of their actions. Rare are the established entrepreneurs in Brazil that have concern with the issue of indiscriminate exploitation of non-renewable natural resources and the imbalance causing the ecosystem. The study shows aspects of environmental protection through the use of existing taxes in national law as a way to encourage taxpayers, are entrepreneurs or not, release them for payment. It also explored the possibilities cited by some States and Cities.

Key- Words: environment protection, not-jurisdictional instruments, tributes.

\section{INTRODUÇÃO}

Faz tempo que se discute sobre os problemas referentes à preservação ambiental e ao desenvolvimento econômico. Durante décadas, meio ambiente e desenvolvimento eram tratados como alternativas: ou se preservava o ambiente ou se desenvolviam as nações. Por motivos diversos, países com tal mentalidade, escolhiam o que entendiam ser o melhor para o homem - o progresso, ou seja, o desenvolvimento econômico. Isso deu origem a situações graves como a desertificação, altos índices de desemprego, a contaminação das águas, o uso imoderado de agrotóxicos, o aumento da miséria, a falta de acesso aos direitos básicos fundamentais como saúde e educação. Entretanto, com o crescimento cada vez maior do movimento ambientalista, chegou-se a outros entendimentos, em que ambiente e desenvolvimento deixam de ser vistos

\footnotetext{
${ }^{33}$ Mestre em Integração Latino-americana pela UFSM/RS. Professora dos Cursos de Direito da UNESAUniversidade Estácio de Sá e do CESAG/SC. Advogada. Mediadora familiar.
} 
como oponentes, e passam a ter a oportunidade de conviver harmoniosamente. Criou-se, enfim, a idéia do desenvolvimento sustentável. Mas, para que o desenvolvimento aconteça de modo adequado e saudável muitos povos vem redimensionando seu estilo de vida, uma vez que o desenvolvimento a qualquer preço vem mostrando seus custos ambientais. Portanto, é urgente que esta conscientização seja global, pois não há outras opções, nem a médio, nem a longo prazo. A humanidade precisa viver dentro da capacidade de suporte do Planeta e integrar conservação e desenvolvimento. Sem perda de tempo.

\section{INSTRUMENTOS DE TUTELA AMBIENTAL}

De acordo com o caput do artigo 225 da Constituição Federal do Brasil é dever da coletividade e do Poder Público a preservação e a proteção dos bens ambientais. Como o meio em que se vive é de natureza difusa e todos têm direito ao meio ambiente ecologicamente equilibrado, implica reconhecer como instrumentos de tutela ambiental não só os atos da Administração ${ }^{1}$ que se destinem a este fim, como também os que emanarem da coletividade, organizada ou não, com a finalidade de sua proteção e preservação.

Segundo a doutrina, existem dois tipos diversos de instrumentos de tutela ambiental: mecanismos não jurisdicionais e mecanismos jurisdicionais de tutela ambiental. Dentro do primeiro grupo dispõe-se do poder de polícia ${ }^{2}$, do direito de informação ${ }^{3}$, da educação ambiental, da ecoetiqueta ${ }^{4}$, consórcios intermunicipais ${ }^{5}$, do estudo prévio de impacto ambiental ${ }^{6}$, do manejo

\footnotetext{
1 Administração e Administração Pública serão tratadas de acordo com a significação ofertada por BOBBIO, Norberto. Dicionário de Política. UnB, 1986, e que diz: "em seu sentido mais abrangente, a expressão Administração pública designa o conjunto das atividades diretamente destinadas à execução concreta das tarefas ou incumbências consideradas de interesse público ou comum, numa coletividade ou numa organização estatal". Já em relação à Administração Pública e Governo (complexo de órgãos que institucionalmente tem o exercício do poder), embora o termo possa ser associado, "não deve ser confundido, pois cada um tem características próprias.

${ }^{2}$ Está qualificado nos artigos 145 , II da C. Federal/88 e artigo 78 do C.T.N.

${ }^{3}$ Condição necessária e essencial para que cada cidadão saiba o que adquire o que utiliza, do que se alimenta. Visa à preservação da espécie, em sentido amplo.

${ }^{4}$ Permite aos produtores colocarem em seus produtos um logotipo, em consideração aos resultados ecológicos globais ao longo de sua atividade econômica (fabricação, distribuição, consumo e uso, até a eliminação após a sua utilização além de considerar a origem das matérias primas e embalagem empregada).

${ }^{5}$ É um ajuste firmado entre municípios visando metas comuns, que são atingidas através de recursos materiais e financeiros de que cada um possui.
} 
ecológico, do zoneamento ambiental, do tombamento ambiental, do direito de antena ${ }^{7}$, dentre outros mecanismos. Alguns com respaldo constitucional e outros com fundamento na Lei $\mathrm{n}^{\circ}$. $6.938 / 81^{8}$.

Fazem parte do segundo grupo, ou seja, meios jurisdicionais de tutela, a ação popular ambiental, a ação civil pública, o mandado de segurança ambiental, o mandado de injunção, etc. É oportuno dizer que, o Poder Público ${ }^{9}$, com a sua atuação ou omissão, pode vir a gerar efeitos de índole nociva ou não, ao meio ambiente. Um exemplo é quando o Legislativo elabora leis, contribuindo para a proteção ambiental, resguardando da exploração do homem certas áreas, ou quando fixa critérios para determinados procedimentos. O contrário também pode ocorrer dando margem à degradação ${ }^{10}$ do meio, quando o mesmo Poder se omite, na tomada de medidas antidilapidatórias. Afinal, é preceito constitucional que "ninguém será obrigado a fazer ou deixar de fazer alguma coisa senão em virtude de lei” (art. 5, II, da Constituição Federal/88). Dentre os instrumentos não-jurisdicionais de proteção ambiental será abordada a tributação ambiental, que quanto mais aplicada, mais vem ganhando a adesão de governos e setores privados.

\subsection{A Tributação Ambiental}

Inicialmente é necessário dizer que o sentido moderno de tributo não corresponde ao

\footnotetext{
${ }^{6}$ Resolução $\mathrm{n}^{\circ}$. 001/86 do CONAMA, artigo $1^{\circ}$, considera impacto ambiental: “ (...) qualquer alteração das propriedades físicas, químicas e biológicas do meio ambiente, causada por qualquer forma de matéria ou energia resultante das atividades humanas que, direta ou indiretamente, afetam: a saúde, a segurança e o bem-estar da população; as atividades sociais e econômicas; a biota; as condições estéticas e sanitárias do meio ambiente e a qualidade dos recursos naturais". Além da Resolução em questão, tal instrumento está definido na Resolução nº 237 do CONAMA, e previsto na Lei da Política Nacional do Meio Ambiente e na Constituição Federal de 1988.

${ }^{7}$ Sobre manejo ecológico, direito de antena, tombamento e zoneamento ver FIORILLO, Celso Antônio Pacheco e RODRIGUES, Marcelo Abelha. Manual de Direito Ambiental e Legislação Aplicável. São Paulo: Max Limonad.

${ }^{8}$ Lei $n^{\circ} .6 .938$, de 31 de agosto de 1981 e o decreto que a regulamenta - Dec. no 99.274 de 06 de jul. 1990. Disponível em:<http://www.mre.gov.br/conamahtml .>> Acesso em 12 ago.2006.

${ }^{9} \mathrm{O}$ ordenamento jurídico de qualquer país dá tratamento diverso aos interesses públicos e privados, pois reconhece à Administração Pública poderes que não são usualmente desfrutados pelos particulares. Seu uso, para ser legal, deve ser normal.

${ }^{10}$ (...) "Nada mais perigoso para a tutela ambiental que um administrador absolutamente livre ou que não sabe utilizar a liberdade limitada que o legislador lhe conferiu". CARVALHO, Edson Ferreira de. RODRIGUES, Gomercindo Clóvis Garcia. "Legislação Ambiental e sua Aplicação no Estado do Acre". Revista da Faculdade de Direito Milton Campos, vol. 3, $\mathrm{n}^{\circ}$. 3, p. 185-211.
} 
primitivo, uma vez que hoje, o termo refere-se a uma fonte normal de recursos para a nação, e é um instrumento de que esta se serve para intervir no domínio econômico, social e político. Antes, "correspondia a uma imposição que o povo vencedor de uma guerra impunha ao povo derrotado, que devia pagá-la, por estar a mercê daquele que o subjugara. Era uma receita parasitária" ${ }^{11}$. Na atualidade, o Estado tem no tributo sua principal fonte de receita, e para obtêla, deve atuar segundo regras de conduta e de organização, vinculando a vontade e a necessidade da Administração Pública às normas legais que regulam a imposição, a fiscalização e a arrecadação tributária, além de disciplinar as relações entre o fisco e o contribuinte.

Estatui o artigo $3^{\circ}$ do Código Tributário Nacional que tributo é "toda prestação pecuniária compulsória, em moeda ou cujo valor nela se possa exprimir, que não constitua sanção de ato ilícito, instituída em lei e cobrada mediante atividade administrativa plenamente vinculada".

A Constituição Federal em vigor classifica os tributos, segundo diversos critérios. Conforme o tipo de imposição, encontra-se dividido em impostos, taxas e contribuições de melhoria, doutrina há muito difundida pelo Código Tributário Nacional ${ }^{12}$. Isto, entretanto, não significa que outras figuras, como o empréstimo compulsório e a contribuição parafiscal, não sejam considerados como tais. Eles o são, mas por não possuírem fatos geradores próprios, e sim correspondentes aos dos impostos e das taxas ${ }^{13}$, o Texto Excelso não quis reconhecer-lhes autonomia embora todos tenham em comum, o traço da economia coativa. Interessam especificamente ao tema em questão, as classificações relativas finalidade (fins objetivados com o tributo), e ao fato gerador (o que dá motivo a cobrança, a origem do tributo):

Através do critério relacionado com os seus fins, diferenciam-se os tributos em fiscais, parafiscais e extrafiscais. Os primeiros visam apenas à arrecadação de recursos financeiros para os cofres públicos e objetivam a sustentação dos encargos que são próprios do órgão central da

\footnotetext{
${ }^{11}$ ZAVARIZI, Índio J. Política do Direito Tributário. Tese (Doutorado em Direito) Florianópolis: UFSC, 1995.

${ }^{12}$ OLIVEIRA, José M. Domingues. "Espécies de Tributos". Revista de Direito Administrativo, nº 183.

13 "Cada tipo tributário apresenta uma conotação distinta, regras diferenciadas; enfim, não são rigorosamente idênticos. Exemplificando: a) as imunidades genéricas só se aplicam a impostos (art. $150 \mathrm{VI}$ ); b) admite-se certa excepcionalidade ao princípio da legalidade para alguns impostos (art. 153,§ $1^{\circ}$ ); c) a anterioridade não se aplica a determinados impostos (art. 153, I, II, IV e VI)”. MELO, José Eduardo Soares de. Curso de Direito Tributário. São Paulo: Dialética.
} 
administração $^{14}$; os segundos, os parafiscais, destinam-se ao custeio de atividades paralelas à da administração pública direta ${ }^{15}$, como a seguridade social, e os últimos, os extrafiscais são os que atendem a outros fins que não sejam os de simples arrecadação, ou seja, são destinados à correção de situações sociais indesejadas e à condução da economia, estimulando ou não certas atividades (artigos 43, $\S 2^{\circ}$, inciso III; 151, inciso I, 153, incisos I e II; e 182, § $4^{\circ}$, da Constituição Federal/88).

A finalidade da arrecadação dos tributos, não teria importância do ponto de vista jurídicotributário (embora o disposto no artigo $4^{\circ}$ do Código Tributário Nacional) ${ }^{16}$, segundo os doutrinadores tradicionais, pois os interesses considerados no momento pré-jurídico da idealização do tributo seriam da esfera de avaliação política do legislador. O destino dos recursos públicos se regeria somente pelo Direito Financeiro, ao regular os gastos das verbas públicas, e não pelo Direito Tributário, que se limitaria a regrar a instituição e a arrecadação dos tributos ${ }^{17}$. Mas, atualmente, os doutrinadores acreditam que o princípio da proporcionalidade condiciona, sim, no momento de elaboração da lei tributária, pois é ele que permite verificar sua adequação aos interesses e fins legítimos, que devem ser considerados no momento da criação do tributo. Com isto, pode-se verificar o controle da constitucionalidade ${ }^{18}$ uma vez que os tributos extrafiscais têm origem constitucional.

Em relação ao fato gerador, esta expressão ficou consagrada no Código Tributário

\footnotetext{
${ }^{14}$ Como impostos de repercussão exclusivamente interna, taxas e contribuições de melhoria.

15 "Quando a arrecadação tributária se desenvolve em busca de recursos que irão sustentar encargos que não são próprios da administração central do Estado, mas que, apesar disto, decorram de atividades que ao Governo interessa sejam desenvolvidas" é o ensinamento de FANUCCHI, Fábio. Curso de Direito Tributário Brasileiro, São Paulo: Resenha Tributária, vol. I, p. 56-58.

${ }^{16}$ Diz o artigo: "A natureza jurídica específica do tributo é determinada pelo fato gerador da respectiva obrigação, sendo irrelevantes para qualificá-la: I - a denominação e demais características formais adotadas pela lei; II - a destinação legal do produto da sua arrecadação".

${ }^{17}$ OLIVEIRA, José Marcos Domingues. op. cit., p. 21

${ }^{18}$ José A. da Silva diz que Constituição reconhece os seguintes tipos de controles: "(1) controle de legalidade dos atos de que resultem a arrecadação da receita ou a realização da despesa, o nascimento ou a extinção de direitos e obrigações; (2) controle de legitimidade, (...) admite exame de mérito para verificar se determinada despesa, embora não ilegal fora legítima; (3) controle de economicidade, (...), para verificar se o órgão procedeu, na aplicação da despesa pública, de modo mais econômico...; (4) controle de fidelidade funcional dos agentes da administração responsáveis por bens e valores públicos; (5) controle de resultados, do cumprimento de programa de trabalho e de metas, expresso em termos monetários e em termos de realização de obras e prestação de serviços". Curso de Direito Constitucional Positivo, São Paulo: Malheiros.
} 
Nacional (artigos 114 a 118), e nas legislações ordinárias, como elemento fundamental para o nascimento do tributo, apesar das críticas de que representaria apenas um dos elementos da obrigação tributária, ou mais propriamente, a sua materialidade. Desde 1966, a Lei $n{ }^{\circ} 5.172$ proclama fato gerador como a situação definida em lei como necessária e suficiente à ocorrência da obrigação tributária, e através dele, classifica os tributos pela tricotomia tradicional, acompanhada pelo Constituição Federal/88 (artigo 145): impostos, taxas e contribuição de melhoria.

Quanto à extrafiscalidade, permite ao contribuinte a opção de escolher o gravame mais ameno ou até nenhum gravame tributário, conforme sua atuação se desenvolva neste ou naquele sentido previsto em lei. Isto ocorre quando o Governo tem interesse em corrigir situações sociais ou econômicas anômalas ${ }^{19}$, e então concorre para que certa atividade seja estimulada, uma vez que desenvolvida, poderá resultar em fatores positivos para os cofres públicos. É um instrumento moderno e vem intervindo no domínio econômico $e$ social, principalmente no que tange a promoção do desenvolvimento regional e setorial, da indústria nacional, etc. em virtude de sua função regulatória, que é tão importante quanto à arrecadatória (ou fiscal).

A extrafiscalidade ocorre através de incentivos fiscais ${ }^{20}$, conhecidos por benefícios ou estímulos fiscais, que se manifestam sob a forma de imunidade ${ }^{21}$, ou de isenções tributárias ${ }^{22}$. É

\footnotetext{
${ }^{19}$ O Governo gaúcho tentou manter abertas as fábricas de calçados na região do Vale dos Sinos quando da concorrência dos produtos chineses que invadiram o País, época em que foram concedidas isenções de tributos com a finalidade de reduzir os custos dos bens nacionais, para se manterem competitivos. Apesar dos esforços, muitas fábricas fecharam, algumas foram para o Ceará e outros estados nordestinos, aumentando o desemprego na região.

${ }^{20}$ Os incentivos fiscais estimulam os contribuintes a fazerem algo que a ordem jurídica considera conveniente, interessante e oportuno, como empregarem recursos na melhoria de equipamentos relativos à sua atividade com vistas à preservação do ambiente (utilização de tecnologias 'limpas', onde as despesas seriam deduzidas como forma de incentivos fiscais). Fonte: COSTA, Regina H. Tributação Ambiental. Direito Ambiental em Evolução. Curitiba: Juruá.

21 "A imunidade reduz as dimensões do campo tributário das várias pessoas políticas, pois se insere no plano das regras negativas de competência. O setor social abrangido pela imunidade está fora da tributação (...) não poderá ser objeto de exploração pelos entes públicos. (...) ao contrário da isenção - não trata da fenomenologia da incidência, porquanto ocorre antes deste momento". Curso de Direito Constitucional Tributário. CARRAZZA, Roque Antônio. Malheiros: São Paulo, p. 401.

${ }^{22}$ Para Rubens Gomes de Sousa "a isenção é o favor fiscal concedido por lei, que consiste em dispensar o pagamento de um tributo devido". Compêndio de Legislação Tributária, São Paulo: 2003, p. 97. Amílcar de Araújo Falcão diz que na isenção ocorre o fato gerador. "O legislador, todavia, seja por motivos relacionados com a apreciação da capacidade econômica do contribuinte, seja por considerações extrafiscais, determina a inexigibilidade do débito tributário. Fato Gerador da Obrigação Tributária. São Paulo: RT.
} 
de frisar-se que, com exceção dos casos de imunidade, os incentivos fiscais que diminuem ou suprimem a carga tributária, só são válidos se, observados os limites constitucionais, surgirem do exercício ou do não-exercício da competência tributária da pessoa política que os concede. Entretanto, a extrafiscalidade manifesta-se também por desestímulos fiscais, que induzem os contribuintes a evitarem condutas que, embora lícitas, são vistas como impróprias, sob os aspectos político, econômico ou social e, mais recentemente, ainda sob o aspecto ambiental.

Na Constituição Federal, observa-se a função extrafiscal da leitura do artigo 158, inciso IV, onde consta que $75 \%$ da arrecadação do ICMS devem ser destinados aos estados para a sua manutenção e investimentos, e $25 \%$ devem ser distribuídos aos seus municípios.

O princípio do poluidor-pagador, aqui tem um papel importante quando interpretado como proibição de subvenções ${ }^{23}$, além das duas facetas imputadas a ele, por OLIVEIRA $^{24}$ e que são:

\begin{abstract}
$1^{a}$ Num sentido impositivo o princípio significa o dever estatal de cobrar do poluidor (no caso, tributar) contribuições públicas pela sua atividade objetivamente poluidora de forma a fazê-lo arcar com o custo dos serviços públicos gerais ou específicos, necessários à preservação e recuperação ambientais ou à fiscalização e ao monitoramento ambientais (fiscalidade); $e$

$2^{\mathrm{a}}$. Noutro sentido, seletivo, o princípio determina prioritariamente ao Poder Público, que gradue a tributação de forma a incentivar atividades, processos produtivos ou consumos environmentally friendly (literalmente, amistosos, adequados sob a ótica ambientalista...), e desestimular o emprego de tecnologias defasadas (...). (extrafiscalidade).
\end{abstract}

É um princípio internacionalmente reconhecido e adotado, por diversas nações sendo relevante ressaltar que o mesmo não conduz a um direito de poluir ${ }^{25}$, embora os exemplos americanos $(\ldots)^{26}$.

\footnotetext{
${ }^{23}$ Em sentido contrário COASE, R. e Dorfman, N. "The Problem of Social Coast", que consideravam "(...) indiferente, se o causador do dano fosse financeiramente responsabilizado ou se a atividade poluidora devesse ser compensada por subvenções ao prejudicado, inviabilizando este princípio, a segunda opção”. (grifos nossos) apud LOBO, Carlos (vol. 2, p. 43)

${ }^{24}$ Direito Tributário e Meio Ambiente. Rio de Janeiro: Renovar.

${ }^{25} \mathrm{Na}$ França, "o princípio compreende a tributação da poluição, a imposição de normas e a atuação de mecanismos diversos de indenização, (...) o mesmo deve, traduzir-se pela abolição de direitos adquiridos em matéria de poluição". COSTA, Regina H., op. cit., p. 299.

${ }^{26}$ Nos EUA são cobrados tributos pela poluição produzida pelos contribuintes, (ex.: sobre o volume do lixo sólido doméstico, a emissão de gases do efeito estufa, sobre lixos contendo materiais perigosos, além de um sistema de licença negociável. "Consideram a poluição um ato lícito, tanto que o Estado pode onerar a sua prática". Observação
}

ISSN 1981-3694

(C) 2008. Departamento de Direito da UFSM. Todos os direitos reservados. 
A Lei do Ar Puro, e outras concessões dos EUA de licenças negociáveis ${ }^{27}$ como as que permitem que as empresas poluidoras comprem licenças relativas à emissão de poluições no ar, são experiências maléficas que legitimam a poluição, e que não devem ser copiadas por outros países. Através desses mecanismos, aqueles empreendimentos e instalações que mantiverem seu índice de emissão abaixo do nível licenciado, podem vender ou ceder seus superávits de permissão a outras empresas, ou usá-los para compensar excesso de emissões em outras áreas de suas próprias instalações.

É um direito de negociar limites de poluição que não pode ser alastrado, além do que, nem deveria existir. Em contraponto, após a assinatura do Protocolo de Montreal sobre as substancias nocivas à Camada de Ozônio, os americanos inovaram com um imposto sobre clorofluorcarbonetos - CFC's, previstos no U.S.Code nº. 26, seção 4681.

\subsubsection{Uma investigação sobre tributos ambientais no Brasil}

O uso de instrumentos tributários para direcionar o comportamento do contribuinte a favor do meio ambiente, bem como a busca de recursos para prestar serviços nesta seara são situações que vem, de longa data, ganhando importância entre os brasileiros (embora iniciativas como a da lei do imposto de renda de 1966$)^{28}$. O estudo abrangeu os tributos que se seguem.

de Karen Oliveira. Anais do Seminário Nacional de Pesquisa e Pós-graduação em Direito. Belo Horizonte: Fac. de Direito da UFMG, 1995, p. 217. (grifos nossos)

${ }^{27}$ O Prof. Hans-Jurgen Ewers, em artigo intitulado "O Programa de um Imposto Ecológico e os seus efeitos sobre o Sistema Tributário Alemão", salienta que observando-se a redução pelo catalisador das quantidades emitidas das substancias formadoras do ozônio (hidrocarbonetos e óxidos nítricos), torna-se claro que uma maior taxação dos veículos sem catalisador poderia ocasionar uma clara redução dessas substâncias. Assim, veículos a motor Otto com catalisador emitem aproximadamente $85 \%$ menos as substâncias poluentes que veículos sem catalisador. Entretanto, há estudos para reformulação do IPVA, buscando descobrir a eficiência deste tributo, tanto para evitar a emissão de gases poluentes, como para estimular uma renovação rápida do parque automobilístico e a instalação de catalisadores nos carros não equipados, deste modo atingindo os objetivos de redução de emissões" Cf. Conselho de Especialistas em Questões Ambientais. Parecer sobre o meio ambiente para um desenvolvimento sustentável e ecologicamente adequado. Stuttgart: Metzler-Poeschel, 1994, FERNANDEZ, José Carrera e GMUNDER, Ulrich (organizadores). Uso eficiente de recursos naturais e uma política tributária ecológica. Salvador: Goethe Institut, 1998, p. 137-162.

${ }^{28}$ Esta Lei inicialmente autorizou as pessoas físicas a abaterem em suas declarações de rendimentos as importâncias empregadas em reflorestamento; as pessoas jurídicas foram autorizadas a descontar do imposto a pagar, até $50 \%$ do valor do imposto, as importâncias aplicadas nessas atividades (art. $1^{\circ}$ ). Como uma das condições a serem satisfeitas pelos contribuintes estabeleceu-se a comprovação de o florestamento ou reflorestamento servir de base à exploração

ISSN 1981-3694

(C) 2008. Departamento de Direito da UFSM. Todos os direitos reservados. 


\subsubsection{Impostos}

Considerando-se o Código Tributário Nacional, em seu artigo 16, os impostos indiretos sobre a produção e o consumo, podem ser bastante utilizados nesta área. Através de um sistema de graduações de alíquotas, isenções e restituições conforme a natureza dos equipamentos ou mercadorias, de forma a se estimular a fabricação de produtos mais eficientes e menos poluentes, e desestimular a produção dos que não tenham estas qualidades, ou cujo modo de produção ocasione poluição. Regina Costa traz exemplos significativos, na área federal:

1. O Decreto federal $\mathrm{n}^{\circ} 755 / 93$ estabeleceu diferentes alíquotas do IPI para veículos movidos a gasolina ( $25 \%$ ou $30 \%$ ) conforme as especificações) e para os movidos a álcool (20 ou 25\%); embora o intuito tenha sido incentivar a produção do álcool visando à diminuição da importação de petróleo, contribuiu para diminuir os níveis de poluição do ar nas cidades; ${ }^{29}$

2. A legislação do imposto de renda, que autorizou a dedução de importâncias empregadas em projetos de reflorestamento (Lei ${ }^{\circ}$ 5.106/66, Decretos n $n^{\circ}$ 93.607/86 e n ${ }^{\circ}$ 96.233/88, 3. A recente Lei $n^{\circ} 9.393 / 96$ que disciplina o ITR, que exclui $d a$ área tributável as áreas de preservação permanente e de reserva legal, as de interesse ecológico para a proteção de ecossistemas e as comprovadamente imprestáveis para qualquer tipo de exploração, declaradas de interesse ecológico (artigo 10, inciso II, alíneas "a", "b" e "c") ${ }^{30}$.

Entretanto, é bom lembrar que a nova lei do Imposto Territorial Rural (ITR) condicionou a isenção do tributo sobre essas áreas, à comprovação da existência delas.

No imposto sobre produtos industrializados (IPI), a regra da seletividade em função da essencialidade do produto, que é obrigatória segundo os ditames do artigo153, $\S 3^{\circ}$, inciso I da

econômica ou à conservação do solo e dos regimes de águas (art. $2^{\circ}$ ). Depois, a legislação exigiu que os projetos florestais servissem não só ao desenvolvimento econômico, mas que "TAMBÉM contribuíssem para a conservação da natureza através do florestamento ou reflorestamento" (Decreto no. 96.233/88 c.c. Decreto nº 93.607/86). Pelo Decreto de 1986 foi determinado que as agências de desenvolvimento encarregadas da administração dos incentivos fiscais que levassem em consideração os aspectos ambientais na análise dos projetos de que se trata e no acompanhamento de seus resultados (art. $8^{\circ}$ ). OLIVEIRA, José M. Domingues, op. cit., p. 31-32. (grifos no original).

${ }^{29}$ Leciona OLIVEIRA que a combustão do álcool não libera monóxido de carbono, como a da gasolina, e que o uso do álcool foi um incentivo ao consumo de combustíveis não-poluentes. Op. cit., p. 30.

${ }^{30}$ Em artigo publicado no jornal O Estado de São Paulo (16.12.96), Antônio H. Benjamin relata: "há matas nativas que não se enquadram nestas categorias, o que vai conduzir sejam as mesmas consideradas pela lei, como áreas improdutivas. Desse modo, o proprietário de área com cobertura florestal ficará em situação difícil; de um lado, deve preservá-la, já que para explorá-la precisa de licença expedida pelo Poder Público; de outro, porém, deve 
Constituição Federal/88, e determinante da intensidade da tributação, permitindo que seja adotada uma alíquota mais gravosa para os produtos industrializados tóxicos ou poluentes.

O princípio da função social da propriedade faz com que os impostos incidentes sobre a propriedade imobiliária propiciem um ótimo contexto para a imposição tributária ambiental. Assim, em relação ao ITR, suas alíquotas devem ser fixadas visando desestimular a manutenção de propriedades improdutivas (art. 153, $\S 5^{\circ}$, da Constituição Federal/88), mas também com o propósito de incentivar a utilização adequada dos recursos naturais e a preservação do ambiente (cf. art. 186, II, do mesmo diploma legal), atendendo assim a exigência constitucional e evitando a desapropriação para fins de reforma agrária.

$\mathrm{Na}$ esfera estadual, o imposto sobre a circulação de mercadorias e prestações de serviços de transporte interestadual e intermunicipal e de comunicações (ICMS), também pode ser seletivo como o imposto sobre produtos industrializados (IPI), em função da essencialidade das mercadorias e serviços (Constituição Federal, art. 155, inciso II, $\S 2^{\circ}$ ). A lei fluminense ${ }^{\circ}$ $2.273 / 94^{31}$, por sua vez autorizou:

(...) o Poder Executivo estadual a conceder prazo especial de pagamento do ICMS para indústria ou agroindústria que utilize "tecnologia inovadora" nas hipóteses que menciona, desde que, entre outras condições, "promova a defesa do meio ambiente". (art. $1^{\circ}, \S$ único). É caso típico de financiamento subsidiado, ou benefício fiscal, a título de postergação do cumprimento da obrigação tributária.

Existe também, em mais de dez Estados brasileiros, o ICMS ecológico tendo como pioneiros Paraná, Minas Gerais, São Paulo, Rio Grande do Sul, Rondônia e Mato Grosso.

No Paraná é um "instrumento que compensa e incentiva financeiramente os municípios que possuem em seus territórios mananciais de abastecimento público para municípios vizinhos e Unidades de Conservação" ${ }^{32}$. A constituição de recursos do ICMS ecológico (Lei estadual n ${ }^{\circ}$ 59/91 e Decreto ${ }^{\circ}$ 974/91) traduz-se em $5 \%$ dos $25 \%$ da arrecadação do ICMS destinado ao

utilizá-la de qualquer modo, mesmo que para pastagem, para não pagar mais imposto, ou para evitar, até, a desapropriação para fins de reforma agrária". Caderno Cidades, "Desastre ambiental anunciado", em 16.12. 96.

${ }^{31}$ OLIVEIRA, José M.D., op. cit., p. 33.

${ }^{32}$ HEISLER JR., Ivo Bernardo. "Projeto ICMS ecológico/Estado do Paraná". Uso Eficiente de Recursos Naturais e uma Política Tributária Ecológica. José C. Fernandez e Ulrich Gmunder (orgs), Salvador: Goethe Institut, 1998, p. 16. 
Fundo de Participação dos Municípios (o qual é repartido entre todos os municípios). Destes 5\%, metade cabe aos municípios com mananciais de abastecimento hídrico e a outra parte àqueles com Unidades de Conservação, e os índices são calculados a partir da aplicação de fórmula, que visa mensurar Coeficiente de Conservação da Biodiversidade - CCB. Caso o município conte com os dois fatores, antes mencionados poderá ser duplamente beneficiado ${ }^{33}$. A possibilidade de receber estes recursos tem contribuído muito para crescerem os investimentos na melhoria ambiental $^{34}$.

Em Minas Gerais a Lei $n^{\circ} 12.040 / 95$, conhecida por Lei Robin Hood, surgiu com a finalidade de favorecer os municípios mais pobres e de menor porte, com aumentos expressivos na cota-parte do ICMS. O critério ICMS ecológico incentiva a preservação dos recursos naturais e o saneamento ambiental (implantação de sistemas de tratamento ou disposição final de lixo e esgotos sanitários) concedendo aos que possuam estes sistemas, em operação e regularmente licenciados junto ao órgão competente, uma parcela adicional do imposto.

\begin{abstract}
Para ser beneficiado com parcela de ICMS sob o critério saneamento ambiental o município deverá atender a um dos seguintes requisitos: 1. Possuir sistema de tratamento ou disposição final de resíduos sólidos urbanos - lixo, que atenda a pelo menos $70 \%$ da população do município (...); ou 2. Possuir sistema de tratamento de esgotos sanitários que atenda a pelo menos $50 \%$ da população do município (...). Artigo $1^{\circ}$, inciso VIII, alíneas a, b e c, da Lei ${ }^{\circ} 12.040 / 95$.
\end{abstract}

O valor é de um quarto dos $25 \%$ do ICMS, repassado de acordo com critérios sociais, culturais e ambientais. Desta forma, os sujos perdem receitas para os limpos. Entretanto, percebe-se desde 2006, que tem havido grande repercussão quanto à criação das Áreas de

\footnotetext{
${ }^{33} \mathrm{O}$ fato deste montante ser retirado daquilo que seria repassado às prefeituras, via FPM, significa que os recursos não saem do Tesouro do Estado, mas sim dos outros municípios que, em princípio, não tem área verde nem mananciais, fazendo uso da água de localidades vizinhas.

${ }^{34}$ Após a implementação da Lei, verificou-se que "75\% dos mananciais apresentaram melhoria quanto ao aspecto qualitativo das águas e da condição ambiental das bacias hidrográficas. Houve também, um aumento de cerca de $80 \%$ no perfil das áreas protegidas do Estado, bem como uma sensível melhoria na qualidade de conservação das mesmas. Em cinco anos de efetivo cumprimento da lei, foram obtidos melhores resultados do que em sessenta anos de políticas publicas sobre áreas protegidas". HEISLER JR., Ivo Bernardo. op. cit., p 164.
} 
Proteção Ambiental, a nível de municípios, o que deve ser recebido com alguma cautela, pois o Estado mineiro não está impondo certas cuidados, o que pode redundar numa "indústria de APAs". (áreas de preservação ambiental). O objetivo do outro critério, unidades de conservação, é compensar os municípios que têm porções de terra comprometidas com essas unidades, que implicam em restrições de uso do solo, e incentivar a criação, implantação e manutenção de UC pelos próprios municípios, contribuindo para descentralizar e consolidar a política de proteção de ecossistemas naturais.

O Estado de São Paulo criou o ICMS Ecológico, a partir de 1993, pela Lei $n^{\circ}$. 8.510, que distribui $1 \%$ do ICMS pertencente aos municípios, onde $0,5 \%$ são destinados aos detentores de Unidades de Conservação e os outros $0,5 \%$ aos municípios possuidores de áreas de barragens e reservatórios de água.

O Estado de Rondônia instituiu o ICMS Ecológico em 1996, através da Lei nº 147/96. O modelo deste estado está embasado no critério ligado às unidades de conservação e terras indígenas. Relevante observar que a lei deste estado prevê a redução do ICMS Ecológico aos municípios cujas unidades de conservação sofram invasões ou outros tipos de agressões.

Em relação ao Estado do Mato Grosso, existe uma proposta de distribuição de 7,5\% do total do ICMS pertencente aos municípios, segundo critérios ambientais. É conhecido ainda o primeiro e interessante convênio verde de $n^{\circ} .51 / 99^{36}$, substituído pelo convênio $n^{\circ} .162 / 02$, autorizando a concessão de isenção do ICMS, nas hipóteses a seguir:

\footnotetext{
Cláusula primeira-(...)

I - saídas internas do estabelecimento produtor agropecuário com destino às Centrais ou Postos de Coletas e Recebimento de embalagens de agrotóxicos usadas e lavadas; II - saídas interestaduais promovidas pelas Centrais ou Postos de Coletas e Recebimento de embalagens de agrotóxicos usadas e lavadas, prensadas, com destino a estabelecimentos recicladores.

Cláusula segunda- A isenção prevista na cláusula anterior alcança ainda a respectiva prestação de serviço de transporte. (grifos nossos).

Cláusula terceira - Ficam os Estados de Mato Grosso e Minas Gerais autorizados a:
}

\footnotetext{
${ }^{36}$ Convênio $n^{\circ}$ 51/99 - Celebrado na $94^{a}$ reunião ordinária do CONFAZ, realizada em João Pessoa, PB. Ratificado nacionalmente pelo Ato Declaratório 01/99, publicado no D.O.U. de 17.08.1999. Substituído pelo convenio ICMS 162/02, ratificado pelo ato declaratório $n^{\circ}$. 01/03, eficaz a partir de 08.01.2003. Outro documento, o Convênio ICMS 58/03 incluiu Goiás, Mato Grosso do Sul, Minas Gerais e Rio Grande do Sul nas disposições do convênio de 2002. Eficácia a partir de 29.07.2003. Pelo Convenio ICMS 138/03 o Estado da Bahia também aderiu a esta concessão tributária-ambiental, que foi ratificada nacionalmente pelo DOU de 06.01.04, através do Ato Declaratório $01 / 04$
} 
I - condicionarem a concessão da isenção à adequação dos produtos mencionados na cláusula primeira ao atendimento a outras normas relativas à política de preservação ambiental;

II -estabelecerem outros procedimentos tributários a serem adotados para operacionalização do presente convênio. (atualizado através do Ato Declaratório 01/04, do CONFAZ)

Além destas disposições existem ações diversificadas, como a do município de Chapada dos Guimarães que destina 40\% do ICMS Ecológico para a preservação de nascentes e ações de Educação Ambiental, enquanto Campo Novo e Tangará da Serra debatem a aplicação dos recursos em áreas indígenas.

O Estado do Rio Grande do Sul estabeleceu o seu ICMS Ecológico pela Lei nº 11.038/97, tendo entrado em vigor a partir de 1998, beneficiando os municípios que possuem áreas de preservação ambiental, e os que têm áreas inundadas por barragens. $\mathrm{O}$ modelo associa o critério ambiental ao critério "área do município", definindo no inciso III, do artigo $1^{\circ}$, da referida Lei, que deverá ser assim repartido entre os municípios: "7\% com base na relação percentual entre a área do município, multiplicando-se por 3 (três) as áreas de preservação ambiental e as inundadas por barragens, exceto as localizadas nos municípios sedes das usinas hidrelétricas, e a área calculada do Estado".

Por outro viés, o Estado do Rio de Janeiro tratou da questão ambiental pela Lei no . 948/85, que serviu de exemplo para muitos outros estados, ao tributar o Imposto sobre a Propriedade de Veículos Automotores (IPVA) dos veículos movidos a álcool com a alíquota menor (2\%), enquanto que os movidos a gasolina tiveram tributação maior (3\%). Em 1999 esta lei foi alterada, pela Lei $n^{\circ} 3335 / 99$, e deferiu alíquota diferenciada nos seguintes casos:

\footnotetext{
Art. 10 - A alíquota do imposto é de:

I - 5\% para embarcações e aeronaves;

II - 4\% para automóveis de passeio e camionetas, exceto utilitários;

III- 3\% para utilitários;

IV - 2\% para ônibus, microônibus, motocicletas e ciclomotores;

V - $1 \%$ para caminhões com capacidade de carga superior a 1 (uma) tonelada e veículos de transporte de passageiros a taxímetro pertencentes a pessoas jurídicas;

VI - 2\% para automóveis movidos a álcool;

VII - 1\% para veículos que utilizem gás natural ou energia elétrica;
}

Mais adiante, o Estado do Rio de Janeiro também concedeu o desconto entre $66 \%$ a $75 \%$ no imposto para os carros com equipamento de gás natural. No âmbito municipal, bom 
mecanismo tem sido o imposto sobre a propriedade predial e territorial urbana (IPTU), uma vez que a propriedade imobiliária urbana também deve cumprir sua função social, conforme previsto na Constituição Federal/88 em seu artigo 182. O requisito é satisfeito quando o imóvel atende as exigências do Plano Diretor da cidade, podendo até receber benefícios fiscais ${ }^{36}$. Em caso de não cumprir o destino urbanístico, o proprietário pode vir a ser penalizado, com a progressividade da alíquota no tempo, prevista tanto na Constituição Federal/88 quanto no Estatuto da Cidade, Lei $\mathrm{n}^{\circ} .10 .257 / 01\left(\operatorname{artigo} 7^{\circ}\right)$.

Quanto ao imposto sobre serviços (ISS), o município pode vir a incentivar serviços que objetivem a preservação ambiental e à atividade econômica, como o turismo ecológico, fazendo gerar renda e empregos. Assim, os proprietários de Reservas de Proteção Permanentes Naturais (RPPNs) terão a possibilidade de tirar proveito da biodiversidade existente nas mesmas, além de poderem fortalecer a imagem de seu empreendimento original - criação de gado ou exploração florestal, por exemplo - através do marketing ambiental. Para tanto, faz-se necessário que tais atividades estejam previstas e aprovadas no plano de manejo da RPPN.

Nos últimos vinte anos, o IBAMA autorizou a criação de cerca de 415 RPPNs, que somam cerca de 800.000 hectares, localizados principalmente nas regiões Sul, Sudeste e Centro-Oeste (dos quais, $70 \%$ pertencem a particulares) ${ }^{37}$. Há ainda, a possibilidade de obter junto ao Fundo Nacional do Meio Ambiente, financiamento de até 200 mil reais por ano, para executar projetos de conservação, através de concessão de crédito agrícola junto às instituições oficiais de fomento, para projetos a serem implementados em propriedades que contiverem RPPN em seus perímetros; possibilidades de cooperação com entidades privadas e públicas na proteção, gestão e manejo da RPPN e, sem esquecer, que a isenção do ITR permanece.

\footnotetext{
${ }^{36}$ Após uma RPPN ser reconhecida pelo IBAMA, o dono da terra nunca mais poderá dar outro destino à área, que adquire caráter permanente de U.C., protegida por lei (tal como o tombamento de uma cidade histórica). As terras podem ser vendidas, mas permanece assegurado o caráter de reserva, com o novo dono. "Os Parques nacionais de Iguaçu (PR), e da Chapada dos Veadeiros (GO), são exemplos de rentabilidade financeira da exploração de um bem natural. Iguaçu recebe anualmente, cerca de um milhão de visitantes, garantindo a arrecadação de R $\$ 2$ milhões só com a cobrança de ingressos (...)". TURAZZI, Deigma, "Investindo na Vida". Revista do Conselho Federal de Engenharia, Arquitetura e Agronomia, 1997, no. 2, p. 84-89. Fonte de dados numéricos: Disponível em: $<$ http://www2.ibama.gov.br/unidades/rppn/>. Acesso em 30 jun 2006.
} 


\subsubsection{Taxas}

Em relação às taxas, tributos de caráter contraprestacional, pelo que reza o artigo 77 do Código Tributário Nacional, possuem como fatos geradores o licenciamento, a fiscalização e a limpeza ou recuperação ambiental, guardando uma razoável proporcionalidade com o custo dos serviços que a justificam. Tributos vinculados, portanto, a uma atividade estatal específica. Como exemplo pode-se citar as taxas de serviço, cobradas pela prestação de serviço público de natureza ambiental e, as taxas de polícia, cobradas pelo exercício de fiscalização e controle da atividade particular, por ocasião da expedição de licenças ambientais.

A Constituição Federal/88 não é explícita quanto a tributação ambiental, mas a Constituição carioca, (...) é clara ao expressar no artigo 258 a determinação da adoção de uma política tributária que implemente o princípio do poluidor-pagador. Em seu artigo 259, assim dispõe sobre taxas ambientais: A utilização dos recursos naturais com fins econômicos será objeto de "taxas" correspondentes aos custos necessários à fiscalização, recuperação e manutenção dos padrões de qualidade ambiental ${ }^{38}$.

No Estado de Pernambuco, a Lei $n^{\circ}$. 10.403/89 alterada pelas Leis $n^{\circ}$. 11.704, de 29/11/99; $\mathrm{n}^{\circ} 11.923$, de 29/12/00, $\mathrm{n}^{\circ} 11.949$, de 09/04/01, e regulamentada pelo Decreto distrital $\mathrm{n}^{\circ}$. 018/2004 (DOE 06/02/04) é outro exemplo de taxa de preservação ambiental (TPA). Vem sendo cobrada de todas as pessoas, não residentes ou não domiciliadas no Arquipélago de Fernando de Noronha, que estejam em visita, de caráter turístico, e calculada em razão dos dias de permanência. Ou seja, o fato gerador é a utilização, efetiva ou potencial, por parte das pessoas visitantes, da infra-estrutura física implantada no Distrito Estadual de Fernando de Noronha e o acesso e fruição ao patrimônio natural e histórico do Arquipélago.

Taxas, portanto, prestam-se á proteção ambiental, seja sob a forma de taxas de serviço (pela colocação ou prestação de serviço público de natureza ambiental, à disposição do contribuinte), seja sob a forma de taxas de polícia (como no caso de fiscalização e controle de atividades dos particulares, principalmente das que possam vir a causar poluição.

\footnotetext{
${ }^{38}$ Op. cit., p. 35.
} 


\subsubsection{Contribuição de Melhoria}

O pressuposto para exigir-se a contribuição de melhoria, é a realização de uma pública que tenha valorizado o imóvel do particular, conforme regras constitucionais. Desde que a obra pública volte-se à preservação ambiental, como por exemplo, a construção de um parque, de um lago artificial, arborização de ruas, proteção contra erosão, aterros e obras de embelezamento, e que tenha relação direta na valorização do bem do contribuinte, pode-se "cobrar este tributo que tem sido relevante para fins de urbanização".

Leciona José Marcos Domingues de Oliveira (2007, p 75), que a Lei do Estado do Rio de Janeiro, $\mathrm{n}^{\mathrm{o}} .1 .364 / 88, "(. .$.$) a par de seu potencial arrecadador, pode transformar-se num elemento$ estimulador de grandes obras de profundo sentido ambiental (extrafiscal). Além do seu caráter utilitário, tais obras contribuem para a educação do povo, sendo que a ignorância tem íntima conexão com a destruição do meio ambiente (...)".

Além desta contribuição, a Constituição Federal/88 prevê outras espécies em seu artigo149, que estão ali qualificadas, por suas finalidades. Podem ocorrer para assegurar a livre concorrência, para preservar o meio ambiente, para garantir a participação dos Estados, dos Municípios e do Distrito Federal no resultado da exploração, nos respectivos territórios, de recursos minerais, etc., mas só podem ser exigidas de quem efetivamente se beneficiar, atuando num dado setor econômico ou de quem, ao assim proceder, causar especial detrimento à coletividade: são as contribuições de intervenção da União no domínio econômico.

\section{CONSIDERAÇÕES FINAIS}

Pelo levantamento efetuado, a política ambiental a nível de Brasil ainda caminha em passos lentos, talvez pela difícil incumbência que vem sendo imposta a sociedade de optar por um modelo sustentável de desenvolvimento, adequada à proteção do meio ambiente. Observa-se que a tributação ambiental já existe nacionalmente, sendo ultrapassada a regra que reconhecia no imposto função essencialmente fiscal. Ao criar novas incidências, ao reaproveitar as já existentes com redistribuição da arrecadação, ao graduar de modo diferente as alíquotas privilegiando 
atividades limpas ou sendo voraz quanto a produções ou consumos poluentes, o que se deve ter em vista é a finalidade ambiental, é a orientação da atuação do contribuinte. Depois, então, deve vir o interesse arrecadatório.

É utópica a idéia de que uma reforma tributária direcionada ao meio ambiente possa ser realizada pela instituição de um único e novo tributo ambiental, como por exemplo, sobre o consumo da energia. Isto superestima a eficiência de um único instrumento e demonstra desconhecimento do complexo sistema tributário nacional. Caso se optasse por uma reforma tributária com finalidades ambientais, esta deveria: 1) eliminar os benefícios fiscais de atividades com efeitos ecológicos negativos; 2) incentivar através de linhas de credito oficiais atividades e produtos ambientalmente corretos (produção limpa); 3) incorporar ao sistema tributário, deduções, amortizações, para investimentos em tecnologias verdes, sem instituir novas imposições fiscais; e, 4) aproveitar os tributos já existentes e fortalecê-los, com alíquotas progressivas (mas com possibilidade de compensações) e direcioná-los para a preservação dos recursos não-renováveis.

É claro que estas ponderações precisam levar em conta ritmos progressivos na taxação, pois tributos ambientais não devem ter efeito de choque econômico, senão terminam tendo efeito contrário ao esperado, uma vez que a carga tributária atual já é extraordinariamente elevada e, o que se busca com a sua utilização é incentivar a não poluição ou a diminuição da mesma.

Uma reforma tributária visando o meio ambiente necessita da eliminação de incentivos que tragam conseqüências negativas a ordem natural. O sistema tributário pode e deve ser instrumento eficiente a serviço de um desenvolvimento sustentável e adequado ao meio ambiente. Basta que ocorra uma reforma tributária em que sejam conjugados harmoniosamente os incentivos tributários ao cidadão, que os reflexos surgirão no meio ambiente. Mas isto depende antes de mais nada, nos dias atuais, de vontade política.

\section{REFERENCIAS BIBLIOGRÁFICAS}

BENJAMIN, Antônio Hermann. Desastre Ambiental Anunciado. Jornal O Estado de São Paulo em 16 dez. 1996, Caderno Cidades. 
BRASIL. Código Tributário Nacional. Lei 5.172, de 25 de dezembro de 1966. PINTO, Antonio Toledo, WINDT, Márcia Cristina Vaz e CÉSPEDES, Lívia. São Paulo: Saraiva, 2007.

BRASIL. Lei $\mathrm{n}^{\mathbf{0}}$. 6.938, de 31 de agosto de 1981 e o decreto que a regulamenta - Decreto $\mathrm{n}^{\circ}$. 99.274 de 06 de julho de 1990. Disponível em:<http://www.mre.gov.br/conamahtml>. Acesso em 12 jul. 2006.

BRASIL. SÃO PAULO. Lei no 10.365 de 22.09.87. Disciplina o corte e a poda de vegetação de porte arbóreo existente no município de São Paulo, e dá outras providencias. Disponível em: < http://www3.prefeitura.sp.gov.br/cadlem/secretarias/negocios_juridicos/cadlem/pesqnumero.asp ?t=L\&n=10365\&a=\&s=\&var=0>. Acesso em 07 jul 2008.

BRASIL. Constituição da República Federativa do Brasil- promulgada em 1988. PINTO, Antônio Luiz Toledo; e WINDT, Márcia Cristina V. dos Santos. São Paulo: Saraiva 2008

BRASIL. Lei Complementar 59/91. Sobre o ICMS no Estado do Paraná. Disponível em:<http://209.85.165.104/search?q=cache:gBYOeGN714IJ:www.pr.gov.br/meioambiente/iap/p df/lei5991.pdf+Lei+Complementar+59/91.+ICMs+no+estado+do+Paran\%C3\%A1.\&hl=ptBR\&ct=clnk\&cd=1\&gl=br>. Acesso em 15 out 2007.

BRASIL. SÃO PAULO. Lei n. ${ }^{\mathbf{0}}$ 8.510, de 29 de dezembro de 1993. Altera a Lei 3.201, de 23 de dezembro de 1981, que dispõe sobre a parcela, pertencentes aos municípios, do produto da arrecadação do ICMS. http://www.semasa.sp.gov.br/scripts/display.asp?idnot=170>. Acesso em 15 out 2007.

BRASIL. MINAS GERAIS. Lei n. ${ }^{0}$ 12.040, de 28 de dezembro de 1995. Dispõe sobre a distribuição da parcela de receita do produto da arrecadação do ICMS pertencente aos Municípios, de que trata o inciso II do parágrafo único do artigo 158 da Constituição Federal/88 e dá outras providências. Disponível em: < http://www.conarq.arquivonacional.gov.br/Media/lei_12040_1995.htm >>. Acesso em 15 out 2007.

BRASIL. RONDÔNIA. Lei Complementar n. ${ }^{0}$ 147, de 15 de janeiro de 1996. Disciplina a distribuição das parcelas do Imposto sobre Operações Relativas à Circulação de Mercadorias e sobre Prestações de Serviços de Transporte Interestadual e Intermunicipal e de Comunicação ICMS, destinadas aos municípios. Disponível $\quad$ em: $<$ http://www.sefin.ro.gov.br/arquivos/legislacao/complementares/LC_147-96.DOC>. Acesso em 15 out 2007.

BRASIL. Resolução $\mathbf{n}^{\mathbf{0}} \mathbf{2 3 7}$ do CONAMA. Disponível em:< http://www.mma.gov.br/port/conama/res/res97/res23797.html. Acesso em 07 jul 2008. 
BRASIL. RIO GRANDE DO SUL. Lei n. ${ }^{0}$ 11.038, de 17 de novembro de 1997. Dispõe sobre a parcela do produto da arrecadação do Imposto sobre Operações Relativas à Circulação de Mercadorias e sobre Prestações de Serviços de Transporte Interestadual e Intermunicipal e de Comunicação (ICMS) pertencente aos Municípios. Diário Oficial do Estado do Rio Grande do Sul, Porto Alegre, 1997.

BRASIL. RIO DE JANEIRO. Lei no 2877 de 22 de dezembro de 1997. Dispõe sobre o Imposto sobre a Propriedade de Veículos Automotores (IPVA). Disponível em: < http://alerjln1.alerj.rj.gov.br/contlei.nsf/c8aa0900025feef6032564ec0060dfff/fa1a422b51621113 0325657a0064293f?OpenDocument>. Acesso em 14 out 2007.

BRASIL. Convênio 51/99 - Relativo ao ICMS do Estado do Mato Grosso, sobre isenção de embalagens de agrotóxicos, usadas e lavadas, prensadas e com destino a estabelecimentos recicladores. Publicado no D.O.U. 27.09.99 e ratificado nacionalmente pelo Ato Declaratório 01/99, D.O.U. $\quad$ de 17.08.99. Disponível $\quad$ em:< http://www.sefaz.am.gov.br/Areas/OpcaoSistemas/SILT/Normas/Legisla\%C3\%A7\%C3\%A30\% 20CONFAZ/Conv\%C3\%AAnio\%20ICMS/Ano\%202003/Conv\%C3\%AAnio\%20ICMS\%20200 3.htm>. Acesso em 07 jul 2008.

BRASIL. MATO GROSSO. Lei Complementar n. ${ }^{\mathbf{7}}$ 73, de 07 de dezembro de 2000. Dispõe sobre os critérios de distribuição da parcela de receita do ICMS pertencente aos Municípios, de que tratam os Incisos I e II do parágrafo único do artigo 157 da Constituição Estadual do Mato Grosso e dá outras providências. Disponível em:<http://www.fema.mt.gov.br/upload/arquivos/197_7279-06DispoesobreReserva ParticularPatrimonioNatural-RPPN 16\%5B1\%5D.03.06.doc>. Acesso em 12 out 2007.

BRASIL. Lei 10.257/01. Estatuto da Cidade. Regulamenta os artigos 182 e 183 da Constituição Federal de 1988 e estabelece as diretrizes gerais de política urbana. Disponível em: http://www.ipplap.com.br/acervoin.php?id=2. Acesso em 12 out 2007.

BRASIL. Decreto Distrital no 018/2004 (DOE 06/02/04). ICMs em Fernando de Noronha. Alterou as Leis $\mathrm{n}^{\mathrm{o}}$. 10.403.89, Lei $\mathrm{n}^{\mathrm{o}}$. $11.304 / 95$ e Lei n. $^{\circ}$ 147/96. Disponível em: $<$ http://www.noronha.pe.gov.br/downloads/decretos/dec-distrital-018-04-novo.doc >. Acesso em 12 out 2007.

BRASIL. SÃO PAULO. Portaria SVMA n⿳0 005/06. Disciplina os critérios e procedimentos de compensação ambiental pela remoção: por corte, transplante, ou qualquer outra intervenção, de caráter excepcional, de vegetação de porte arbóreo para viabilização de projeto de edificação, parcelamento do solo e obras de infra-estrutura e em casos de interesse público e/ou social. Disponível em: <http://plantasonline.prefeitura.sp.gov.br/legislacao/lei_int.php?id=1146>. Acesso em 07 jul 2008.

BOBBIO, Norberto. Dicionário de Política. Trad. de J. Ferreira et alii. UnB, 2006. 
CARRAZZA, Roque Antônio. Curso de Direito Constitucional Tributário. 22a ed., São Paulo: Malheiros, 2006.

CARVALHO, Edson Ferreira de. RODRIGUES, Gomercindo Clóvis Garcia. Legislação Ambiental e sua Aplicação no Acre. Revista da Faculdade de Direito Milton Campos. Vol. 3, Belo Horizonte, 1996, pp.185-211

Constituição do Estado do Rio de Janeiro - in Direito Ambiental Aplicado. Fiorindo David Grassi. Frederico Westphalen: URI, 1995, 390 p.

Constituição do Estado de São Paulo in Direito Ambiental Aplicado. Fiorindo David Grassi. Frederico Westphalen: URI, 1995, 390 p.

COSTA, Regina Helena. "Tributação Ambiental" in Direito Ambiental em Evolução. Vladimir Passos de Freitas (org) Curitiba: Juruá, 2002, 398 p.

FALCAO, Amílcar. Fato Gerador da Obrigação Tributária. São Paulo: Revista dos Tribunais.

FANUCCHI, Fábio. Curso de Direito Tributário Brasileiro. São Paulo: Resenha Tributária, 1976, vol. I, 254 p.

FERNANDEZ, José Carrera; GMUNDER, Ulrich. (orgs.) Uso eficiente de Recursos Naturais e uma Política Tributária Ecológica. Salvador: Goethe Institut, 1998.

FIGUEIREDO, Marcelo. "Tributos e Meio Ambiente". Anais do 1 Congresso Latino Americano de Direito sobre As Fronteiras Ambientais, Consumistas e Concorrenciais do MERCOSUL. São Paulo: Marília, 1999.

FIORILlO, Celso Antônio Pacheco e RODRIGUES, Marcelo Abelha. Manual de Direito Ambiental e Legislação Aplicável. São Paulo: Max Limonad: São Paulo, 640 p.

FREITAS, Vladimir Passos de. Direito Administrativo e Meio Ambiente. Curitiba: Juruá, 2006.

Direito Ambiental em Evolução. (org.) Curitiba: Juruá, 2002, 398 p.

GARCIA, Augusto Ribeiro. A propriedade e as leis ambientais. Gazeta do Paraná. 29.11.98.

GRASSI, Fiorindo David. Direito Ambiental Aplicado. Frederico Westphalen :URI, 390 p. 
HEISLER Jr, Ivo Bernardo. "Projeto de Lei sobre ICMs Ecológico do Estado do Paraná" in Uso eficiente de Recursos Naturais e uma Política Tributária Ecológica. FERNANDEZ, José Cabrera; GMUNDER, Ourice (orgs.). Salvador: Goethe Institut, 1998.

IBAMA. Instituto Brasileiro do Meio Ambiente e dos Recursos Naturais Renováveis. Dados sobre RPPNs. Disponível em:< http://www2.ibama.gov.br/unidades/rppn/>. Acesso em $1^{\circ}$ ago 2007.

KRELL, Andreas Joachim. "O sistema jurídico de proteção ambiental da Comunidade Européia - modelo para o Mercosul?" in MERCOSUL, seus efeitos jurídicos, econômicos e políticos nos Estados-membros. Maristela Basso (org.), Porto Alegre: Livraria do Advogado, 1995.

LOBO, Carlos Baptista. Imposto Ambiental. Análise jurídico-financeira. Revista Jurídica de Urbanismo e Meio Ambiente, ${ }^{\circ}$ 2. Coimbra: Almedina, 1994, pp. 11-50.

MELO, José Eduardo Soares. Curso de Direito Tributário. São Paulo: Dialética, 2006

OLIVEIRA, José Marcos Domingues. Direito Tributário e Meio Ambiente. Rio de Janeiro: Renovar, 2007, 120 p.

-------. Espécies de Tributos. Revista de Direito Administrativo, ${ }^{\circ} 183$.

-------. Meio Ambiente - Tributação e Vinculação de Impostos. Cadernos de Direito Tributário, $n^{\circ}$ 56, abr/jun. 1991.

OLIVEIRA, Karen Alvarenga. Poluidor-Pagador:solução tributária para a questão ambiental? Anais do IV Seminário de Pós-graduação em Direito da UFMG. Belo Horizonte: UFMG, 1995.

RIBEIRO, Maurício Andrés; LOPES, Ana Lúcia e RODRIGUES, Ludmila Alves. ICMS Ecológico - MG. Jornal Diário do Comércio, Curitiba, 1998.

SILVA, José Afonso Da. Direito Constitucional Positivo. São Paulo Malheiros, 2007.

SOUZA, Rubens Gomes de. Compêndio de Legislação Tributária. ed. póstuma. São Paulo: Resenha Tributária, 1991.

STOURM, M. Manual de Ciência das Finanças. São Paulo: Saraiva 1980.

TURAZZI, Deigma. Investindo na Vida. Revista do Conselho Federal de Engenharia, Arquitetura e Agronomia, 1997.

VENTURA, Deisy de Freitas Lima. Monografia Jurídica. Uma visão prática. Porto Alegre: Livraria do Advogado, 2006, 152 p. 
ZAVARIZI, Índio Jorge. Política do Direito Tributário. Tese (Doutorado em Direito) Florianópolis: UFSC, 1995. 